\title{
Effect of treatment and drying method (Solar and convective) on physico-chemical quality of dried moringa leaves
}

\author{
Kanika Aggarwal ${ }^{1}$, Manpreet Singh ${ }^{2}$ and Ruchika Zalpouri* \\ Department of Processing and Food Engineering, Punjab Agricultural University, Ludhiana (Punjab) India \\ (Email : zalpouri28@gmail.com)
}

\begin{abstract}
Moringa is one of the promising crop high nutritional and therapeutic values. While drying of moringa leaves, there is significant loss in physical, chemical and nutritional composition of leaves. So, the present study was conducted to investigate the effect of different treatment and drying method (solar and convective) on physico-chemical quality of moringa leaves. Moringa leaves that were sorted, washed and surface dried were considered non-treated whereas leaves that were blanched at 7.5 min after sorting were considered treated. The following samples were dried in three dryers viz., PAU advanced domestic solar dryer, PAU domestic solar dryer and convective tray dryer. Samples that were treated had better physico-chemical quality than untreated sample. Similarly, samples dried in PAU advanced domestic solar dryer had better quality retention i.e. had low moisture content, low colour change, higher protein content, higher ascorbic acid and higher total antioxidant activity.
\end{abstract}

Key Words : Moringa, Blanching, Solar dryer, Convective tray dryer, Physicochemical quality

View Point Article : Aggarwal, Kanika, Singh, Manpreet and Zalpouri, Ruchika (2021). Effect of treatment and drying method (Solar and convective) on physico-chemical quality of dried moringa leaves. Internat. J. agric. Sci., 17 (2) : 228-233, DOI:10.15740/HAS/IJAS/17.2/ 228-233. Copyright@2021: Hind Agri-Horticultural Society.

Article History : Received : 22.02.2021; Revised : 26.02.2021; Accepted : 14.03.2021

\footnotetext{
* Author for correspondence :

${ }^{1}$ College of Agricultural Engineering and Technology, Ludhiana (Punjab) India (Email: kanikaggarwal210@gmail.com)

${ }^{2}$ Department of Renewable Energy Engineering, Punjab Agricultural University, Ludhiana (Punjab) India (Email : manpreet-sesa@pau.edu)
} 